\title{
Factors Promoting and Hindering Performance of Unit Nurse Managers at Kamuzu and Queen Elizabeth Central Hospitals in Malawi
}

\author{
Caroline Chitsulo, Mercy Pindani, Idesi Chilinda, Alfred Maluwa \\ Kamuzu College of Nursing, University of Malawi, Lilongwe, Malawi \\ Email: aomaluwa@kcn.unima.mw
}

Received 20 October 2014; revised 19 November 2014; accepted 30 November 2014

Copyright (C) 2014 by authors and Scientific Research Publishing Inc.

This work is licensed under the Creative Commons Attribution International License (CC BY). http://creativecommons.org/licenses/by/4.0/

\section{(c) (i) Open Access}

\begin{abstract}
Unit nurse managers in Malawi experience many challenges in the course of performing their roles. This affects their performance and service delivery including the quality of nursing care to patients. This study was conducted to determine the factors that hindered performance of unit managers in relation to expected quality of nursing services at two referral facilities (Kamuzu and Queen Elizabeth Central hospitals) in Malawi. These two central hospitals have the same structural settings and both offer specialized tertiary health services. A quantitative descriptive design was used to guide the planning and implementation of the study. Purposive sampling was used to select the two major hospitals in Malawi and all available 37 unit nurse managers during the time of the study at the two hospitals participated in the study. Data were collected using semi-structured questionnaires after seeking consent from the participants and were analyzed using SPSS version 16.0. The major roles identified by the unit managers were supervision $(75.6 \%, n=28)$ and coordination $(70.3 \%, n=26)$. Other roles such as team leader, liaison officer, research allocator, monitor and facilitator were rated by very few participants. Findings of the study showed that performance of unit nurse managers was affected by inadequate material $(86.4 \%, \mathrm{n}=32)$ and human resources $(94.5 \%, n=35)$ and lack of managerial skills $(5.4 \%, n=2)$. In addition, the unit managers perceived their role to be stressful $(38.9 \%, n=14)$ and challenging $(47.2 \%, n=17)$. Therefore, there is a need to provide adequate material and human resources to the wards of the two central hospitals to enable the unit managers perform their duties efficiently.
\end{abstract}

\section{Keywords}

Unit Nurse Manager, Quality of Nursing Care, Managerial Skills, Level of Performance, Role of 


\section{Introduction}

Effective nursing management and leadership are essential for the provision of desired patient care that will contribute to the improvement of any country's health indicators. The nurse manager is the key individual whose leadership can directly influence functions of the nursing service department and ensure that desired quality of nursing services is achieved. The nursing service department globally and in Malawi is one of the disciplines that form a bigger part of the health care delivery system in a hospital where nurses constitute more than half of the health service work force [1].

The crux of every management job lies in the jobholders' capacity to obtain the commitment of people to the objectives of the organization thus exercising appropriate leadership. Ideas about leadership in management roles range from the ideal approaches to scientific management. Yoder-Wise [2] describes health care delivery systems as businesses that are economically driven with emphasis on the provision of the highest quality care at affordable prices. To perform the duties and activities associated with the managerial roles, the unit manager must possess a comprehensive set of skills and competencies and be able to deal effectively with the forces which represent opportunities and threats to the organization [2].

Today's demanding and dynamic health care work environment requires the nurse managers to have multiple skills and to constantly upgrade their skills so that they can take on extra work outside their own specific job area of nursing. Further, Craven and Hirnle [3] argue that nurses must be skilled in the techniques of business management for them to be effective in any management role.

Hewson [4] defined middle level managers in the health services context, within a hospital as nurses that managed a number of wards within a directorate or multidisciplinary health care team. In the Malawian context middle level nurse managers are called unit nurse managers and are responsible for the overall functioning of a nursing unit. A nursing unit at a central hospital comprises more than two wards. For example, the surgical unit comprises male, female and high dependent wards. The unit manager is therefore the overall in charge of the unit regarding nursing services and performs multiple roles in the unit so as to ensure delivery of quality and comprehensive nursing and health services. The roles include: planning for the unit, facilitating educational needs of subordinates and nursing students, decision making, and any other managerial responsibilities. The complexities in performing every day roles and the dynamic, highly demanding environment that unit managers work, affect not only their performance in influencing the quality of nursing services but also client care outcomes [5].

The health indicators for Malawi are poor despite the establishment of primary health care in the 1970's. The maternal mortality rate (MMR) is high at 675 deaths per 100,000 live births and the child mortality rate of 112 per 1000 live births according to the Malawi Demographic Health Survey [6]. This indicates that the quality of health services that are being provided is not achieving the desired patient or client outcomes. In Malawi restructuring of the nursing profession ladders was done with the aim of achieving the desired quality patient care outcomes. Unit managers were deployed at unit level to direct nursing staff and initiate activities to improve the quality of nursing services.

Doctors, nurses and other health stakeholders have expressed dissatisfactions on the quality of nursing services rendered in most clinical settings despite the presence of unit managers. In support of this, the Nurses and Midwives Council of Malawi [7] and media reports have cited the alleged malpractices and negligence by nurses which are on the increase despite the presence of unit managers. In view of the above observations, the deployment of managers to the units has not influenced the quality of nursing services that is expected by the clients as well as other health professionals. The above issues indicate that there must be factors that are influencing the performance of unit nurse managers in clinical settings. Thus there is a need to determine the factors that affect the performance of unit managers.

\section{Methodology}

A descriptive study design which utilized quantitative data collection and analysis method was used to guide the planning and implementation of the study to achieve the desired objectives. The study was designed to collect 
information on areas such as the biographical or psychological characteristics of individuals, the nature of particular social structures, practices, or processes, the prevalence and distribution of certain health states, or the arrangement and functioning of particular institutions and organizations [8]. The study aimed at obtaining information about the performance of unit nurse managers and was conducted in Lilongwe and Blantyre districts at Kamuzu Central and Queen Elizabeth Central hospitals respectively. Purposive sampling method was used to select the two major hospitals in Malawi and the whole population comprising 37 unit managers participated in the study.

\subsection{Inclusion Criteria}

To be recruited for the study, participants had to be unit nurse managers working as a ward in-charge for a period not less than three years at Kamuzu and Queen Elizabeth Central hospitals. They were also expected to show willingness to participate and share their experiences in the study.

\subsection{Ethical Consideration}

A formal approval of the research proposal was obtained from the College of Medicine Research and Ethics Committee (COMREC) in Malawi. Permission was also sought from the Hospital directors of Kamuzu and Queen Elizabeth central hospitals. Verbal and written consent were obtained from the participants after they were briefed about the study. The information included the purpose of the study, its benefits and consequences, to the individual, institution and the nation as a whole. The participants were told that data would not be shared with other people except for the research supervisor and other selected faculty members. Numbers were used instead of names of participants to ensure confidentiality and anonymity. Participants were told that participation was voluntary and that they had the right to refuse to participate or withdraw from the study at any time if they so wished without any resultant penalties.

\subsection{Data Collection}

Data were collected by the principal investigator for a period of two months using semi-structured questionnaires after seeking consent from the participants. All available unit managers (37) at the time of the study consented and participated in the study. The interviews were conducted at a private place. The participants were identified by the chief nursing officers of Kamuzu and Queen Elizabeth Central hospitals. All the interviews and discussions were carried out in English because all participants were able to communicate in English. The questionnaires consisted of both closed and open-ended questions. The discussions concentrated on roles, responsibilities and skills for unit nurse managers, factors hindering performance of unit nurse managers, factors promoting performance of unit nurse managers and strategies to improve performance. Field notes were manually taken to aid the data collection process. Interviews lasted between 30 and 45 minutes. The questionnaire was pretested to determine its validity and reliability. The pretesting was done at Bwaila hospital which has almost similar characteristics with the two hospitals under study. The tool was administered to five nurse managers at unit nursing management level to check if the questions were clear and if they could yield the same responses from the participants. Data were analyzed using SPSS version 16.0.

\section{Results}

\subsection{Demographic Characteristics of the Participants}

Response rate of the study was $82.2 \%$ (37). Table 1 gives characteristics of the respondents.

\subsection{Roles, Responsibilities and Skills of the Unit Nurse Managers}

Results for the roles, responsibilities and skills of unit managers are shown in Table 2. The major roles identified by the participants were supervisor $75.6 \%$ (28) and coordinator $70.3 \%$ (26). The other roles such as team leader, liaison, research allocator, monitor and facilitator were rated to be less important in the multidisciplinary team at their places of work.

Results also indicate that $97.3 \%(n=19)$, supervised their staff on daily basis and that $51.4 \%(n=15)$ of the participants used check lists to effectively supervise their staff. 
Table 1. Characteristics of the respondents.

\begin{tabular}{|c|c|}
\hline Characteristics & Percentage \\
\hline \multicolumn{2}{|l|}{ Sex } \\
\hline Male & $2(5.4 \%)$ \\
\hline Female & 35 (94.6\%) \\
\hline Total & $100 \%$ \\
\hline \multicolumn{2}{|c|}{ Highest professional qualification } \\
\hline Post basic degree & 17 (45.9\%) \\
\hline B.Sc. degree & $10(27 \%)$ \\
\hline Certificate in nursing & $6(16.2 \%)$ \\
\hline Diploma & $4(10.8 \%)$ \\
\hline Total & $37(100 \%)$ \\
\hline \multicolumn{2}{|l|}{ Age } \\
\hline $25-30$ & $6(16.2 \%)$ \\
\hline $31-36$ & 7 (18.9\%) \\
\hline $37-42$ & $8(21.6 \%)$ \\
\hline $43-47$ & 3 (8.1\%) \\
\hline Over 48 & 13 (35.1\%) \\
\hline Total & 37 (100\%) \\
\hline \multicolumn{2}{|l|}{ Years of experience } \\
\hline $1-5$ & 30 (81.1\%) \\
\hline $6-10$ & $1(2.7 \%)$ \\
\hline $11-15$ & $2(5.4 \%)$ \\
\hline Over 15 & $4(10.8 \%)$ \\
\hline Total & $37(100 \%)$ \\
\hline
\end{tabular}

Table 2. Roles of the unit nurse manager.

\begin{tabular}{|cc}
\hline Characteristics & Percentage \\
\hline Plays the role as & \\
\hline Coordinator & $26(70.3 \%)$ \\
Supervisor & $28(75.6 \%)$ \\
Facilitator & $12(32.4 \%)$ \\
Team Leader & $19(51.3 \%)$ \\
Liaison & $13(35.1 \%)$ \\
Resource allocator & $13(35.1 \%)$ \\
Monitor & $13(35.1 \%)$ \\
\hline
\end{tabular}


The unit nurse managers related their roles and the job responsibilities that were attached to the role of the position of unit nurse managers. Staff supervision was rated by $91 \%(n=34)$ of the participants. Other activities that were rated by most of the participants were; organizing human and material resources $89.2 \%(n=33)$, coordinating unit activities 83.7\% ( $\mathrm{n}=31)$, planning for unit activities $81.1 \%(\mathrm{n}=30)$ and budgeting for the unit $62.1 \%(n=23)$.

\subsection{Unit Nurse Managers' Perception of Their Role}

The role of unit management was perceived as being challenging and stressful by $47.2 \%(n=17)$ and $38.9 \%$ ( $n$ $=14$ ) of the participants respectively (Figure 1). Only a few participants perceived their roles to be complex and demanding (Figure 1).

\subsection{Skills of Unit Nurse Managers}

The skills that were rated by most of the participants were: decision-making $86.5 \%(\mathrm{n}=32)$, communication and interpersonal skills 83.8\% $(n=31)$, supervisory 75.7\% $(n=28)$, problem solving 70.3\% $(n=26)$ and critical thinking 59.5\% $(\mathrm{n}=22)$. None of the participants indicated financial management skills as being important but $62.1 \%(n=23)$ of the participants indicated budgeting for the unit as one of their job responsibilities.

\subsection{Factors Hindering Performance of Unit Nurse Managers}

Majority $94.5 \%(n=35)$ of the participants identified inadequate human resources and inadequate material resources $86.4 \%(n=32)$ as main factors that hinder good performance. Twenty-four percent $(n=9)$ indicated absenteeism by personnel and rudeness among nurses and supporting staff while $21.6 \%(n=8)$ and $5.4 \%(n=2)$ reported poor coordination with other departments and lack of training in management skills respectively.

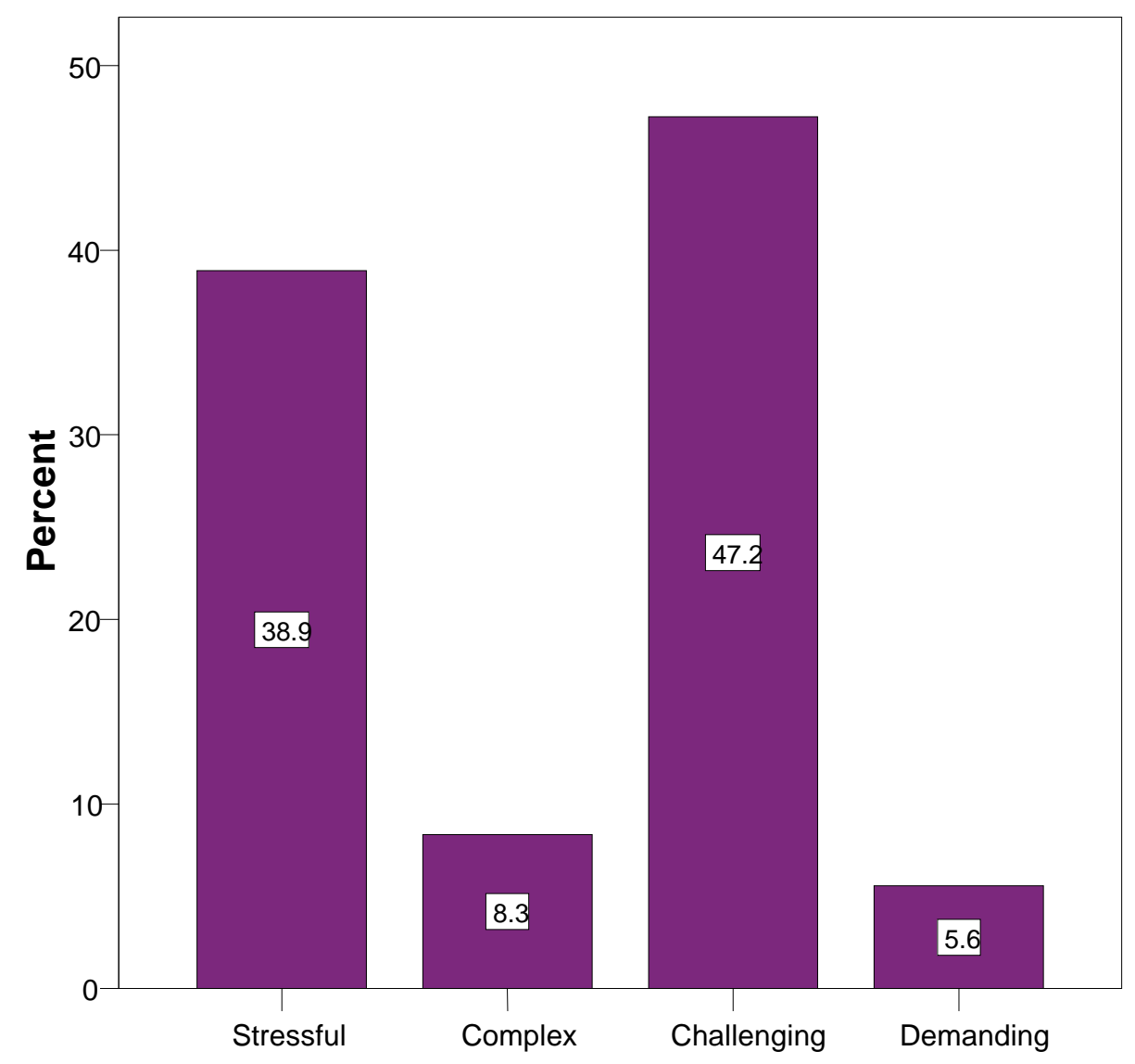

Figure 1. Unit nurse managers' perception of their role. 


\subsection{Factors Promoting Performance of Unit Nurse Managers}

Most of the participants stated that good communication and interpersonal relationships from their supervisors was very important as they were doing their work. Participants indicated that good communication is required by unit nurse managers during staff meetings $94.6 \%(n=35)$, when giving handovers $89.2 \%(n=33)$ and in reports $73 \%(n=27)$. Participants also identified availability of management tools in their work places as one of the factors that promote performance. Forty-three percent $(n=16)$ indicated that they were able to use management tools available in their work units to guide their work. However, the results also indicated that not all participants used management tools even though the tools were available in their units. Ward philosophy was used by $59.5 \%(n=22)$ of the participants; ward objectives were used by $(75.7 \%(n=28)$; and ward policies were used by only $5.4 \%(n=2)$. It was also noted that all participants $100 \%(n=37)$ needed authority to make decisions concerning patient care and to mobilize material resources on their own when the hospital's management failed to do so. Only 8.1\% $(n=3)$ of the participants indicated they were motivated with the educator role during their work.

\subsection{Strategies to Improve Performance}

Most of the participants 67.5\% $(n=25)$ indicated that the hospital management should make supplies always available in the units to assist unit nurse managers do their work effectively. Some participants $64.9 \%(n=24)$ stated that the senior nursing management should support them in instilling discipline among the staff while 54.1\% $(n=20)$ stated that the hospital management should provide enough nurses at all times to facilitate the delivery of quality nursing services. Few participants $10.8 \%(n=4)$ wanted the hospital management to provide training in management to improve the performance of unit nurse managers and quality of nursing services. Another $10.8 \%(n=4)$ of participants wanted the nursing management to enforce the use of management tools by all unit nurse managers to guide them as they do their work.

\section{Discussion}

\subsection{Roles, Responsibilities and Skills for Unit Nurse Managers}

Unit nurse managers have many roles such as coordinator, supervisor, team leader, liaison officer, resource allocator and monitor. This is necessary because nurse managers must lead not only the nursing workforce but also other health professionals in meeting the demands of the ever changing health care environment. However the findings indicated that some unit nurse managers perform these roles without using management tools. For example, although unit managers said they supervise their subordinates it is shown that some of the participants did not use any supervisory tools such as a check list to supervise their units' staff. To effectively perform the supervisory role, unit nurse managers need to have appropriate skills and supervisory tools like a checklist. Without a checklist, it is unlikely that unit nurse managers could effectively supervise their staff, as a result the delivery and quality of nursing services is negatively affected. The reason could be that unit nurse managers did not have the skills to use the tools. The hospital's management specifically the senior nursing management is responsible for ensuring that the unit nurse managers are provided with the necessary tools and skills to perform effectively [9].

The results also indicated that coordinating unit activities was identified as one of the major roles played by unit nurse managers. Unit nurse managers play a very important role in coordinating the activities of the various members of the multidisciplinary team in the units. Coordination ensures synergy and achievement of the desired unit's and hospital's goals and the delivery of quality health services. Although a large proportion of the participants indicated that coordinating the unit's work activities was one of their major roles, it was not known whether this role was performed effectively.

The roles for unit nurse managers have expanded over the years, in the dynamic complex work environment of health care delivery. Unit nurse managers are expected to take a leading role in managing human, material and financial resources of the organizations they work for. In addition they play essential roles in providing input and leadership for managing change, morale, retention and direction of staff attitudes towards changing organizational structures. Unit nurse managers therefore, need to develop an understanding of their expanding roles, the complexity and diversity of the health care environment in order to effectively perform their role in the delivery of quality health services [10]. 


\subsection{Nurse Managers' Perception of Their Role}

The unit nurse manager's role was perceived as challenging and stressful due to inadequate human and material resources, high work load and high expectations from patients. These results are similar to those of Loo and Thorpe [11] who described nursing as stressful and challenging career. In a similar study, Jamal and Baba [12] reported that female nurse managers experienced multiple role-stresses when they combined paid work, especially full time work, with family and child rearing responsibilities. Other studies [13] emphasized the stressful nature of nursing to the extent that many nurses are leaving the field for less exhausting careers. It is imperative that unit nurse managers are available to guide, direct, and support staff [10]. However, these functions are difficult to accomplish without adequate resources. It is therefore important that supportive structures are put in place in the nurse work environments to help the unit nurse managers effectively manage different problems and effectively cope with work stress. For example, senior management must be more supportive; subordinates must become cooperative and colleagues more collaborative [14].

\subsection{Functions and Job Responsibilities of Unit Managers}

Participants were aware of their job responsibilities that were attached to the role of the position of unit managers, probably due to the fact that majority of them had job descriptions. However, a few managers did not have job descriptions. Results that a small proportion of the nurse managers did not have job descriptions raises concerns because it means that the nurse managers did not have a clear role definition, thus they did their job without direction. Unit nurse managers need to have a clear role definition and boundary in order to perform their role effectively [10]. The roles and responsibilities of the nurse manager still remain unclearly defined in many hospitals. They work without direction, as a result they experience job dissatisfaction and their morale goes down [10].

\subsection{Skills of Unit Nurse Managers}

Unit nurse managers need to have a variety of skills to perform multiple roles attached to their positions [14]. These skills enable the unit nurse managers to understand the organizational context, manage resources effectively and facilitate delivery of quality health services. Communication and interpersonal skills were one of the five most important skills which were largely indicated by the participants. This was so, because in the course of their work they interacted with different types of people like clients and their family members, other health professionals and health workers. Participants also stated that they exchanged a lot of information with different people within their work environment. These findings were similar to Surakka [10], who found that the nurse manager's work involved a great deal of communicative activities, such as, developing and receiving information in writing, orally, by phone, or by e-mail. Nurse Managers have a responsibility to make information available to all service providers for effective decision making. According to Mathena [15], social skills are one of the skills nurse managers should also have. This is the ability to manage relationships with others so that the nurse manager can build networks, bridge differences and develop rapport with a wide variety of constituencies [14].

Results indicate that nurse managers need a variety of skills to perform the various managerial activities relevant to different management levels. Similarly, another study [15] reported that general skills, interpersonal skills and staff development were rated by nurse managers as the top three categories that were most important to their success as managers. Financial management skills were not perceived by the participants as one of the important skills for their effective role performance. If participants did not perceive financial management skills as one of the important skills to the performance of their role; it could mean they did not have adequate knowledge and skills in financial matters. It could also mean that these participants were not much involved in financial matters. These findings relate to other studies [16] which reported that nurse managers indicated skill deficit in managing their units' budgets. Unit nurse managers need to have financial skills to be able to understand issues of budgeting and resource procurement and management [16]. They cannot budget and plan for their units if they do not have knowledge and skills in financial management. As a result the lack of planning impact negatively on the availability and use of resources in the unit and hence adversely affecting the delivery of nursing and health services. Current nurse managers assume responsibility for multiple areas, disciplines or skill levels and assume accountability for many initiatives that cross departmental and even institutional lines. In view of the above traditional nurse manager's competencies are not adequate to assume broader areas of their role, more 
global role expectations, or to lead staff through rapidly changing health care environments. It is therefore important that unit Nurse Managers have management, leadership as well as professional skills to effectively perform their role.

\subsection{Factors Hindering Performance of Unit Managers}

Participants indicated the need for drugs, such as antibiotics and pain killers, equipment of different types and various supplies to effectively manage their units and facilitate the delivery of quality nursing services. They shoulder enormous responsibility for the hospital's success or failure as they influence use of resources and the quality of nursing care and patient outcomes. These results suggest that participants could not deliver the desired quality of nursing services without the availability of adequate material resources. Similarly, another study [17] found that nurse managers in selected Malawian hospitals lacked material resources and this affected delivery and the quality of nursing care. These results are similar to those reported by Loo \& Thorpe [11] that nurse managers identified material and human resources as some challenges that affected their work. In addition to equipment and supplies unit nurse managers needed adequate information for effective decision-making. The quality of nursing resources determines the organization's ability to provide care at the desired professional standards. Therefore, inadequate material resources can affect the work of both nurses and nurse managers. The public and other health professionals expect nurse managers and nurses to perform to a certain standard, but due to lack of resources they are unable to do so. This strains the relationship between the nurse managers, nurses, health professionals and the public; as a result the Nurse Managers are demotivated hence affecting the morale of their nursing staff. Similarly, another study [17] also found that shortage of staff was one of the major challenges that nurse managers in selected hospitals in Malawi reported. Aiken et al. [18] found that higher nurse-patient ratios increased patient mortality and that an increased workload had detrimental effect on both the nurse managers' and nurses' experience of work life. Better staffing was found to be positively associated with high quality of care [18]. It is therefore important that unit nurse managers are provided with adequate numbers and the right mix of nursing staff, to effectively perform and achieve the desired quality of nursing services in the units.

Results indicated that more than half of the participants had not attended any refresher courses to update their professional and managerial skills. Without attending refresher courses and other profession related training can result in knowledge and skill deficiency which negatively affect the quality of nursing services and image of the nursing profession. Although the participants recognized the skills that were vital to their success, they did not perceive their learning needs to be critical. Since most of the participants had a Bachelor of Science Degree in Nursing, they did not perceive continuous professional development as a priority. The other possible explanation could be the length of tenure that is reflected to the nurse manager role at the organization. Mathena [15] stated that nurse managers that have long years of experience in the management positions might not perceive professional development as a priority.

\subsection{Factors Promoting Performance of Unit Nurse Managers}

Majority of the participants indicated that good communication and interpersonal relationship among health care professionals was a positive aspect of their role. Participants were able to achieve unit and hospital goals through effective communication and collaboration with other health professionals. Goals and Information about patient care were shared and discussed in meetings at unit and hospital level and also through ward and units reports and handovers. Attending meetings also furnished the participants with information that helped them to make effective decisions concerning patient care. Results also showed that only few participants attended hospital management meetings. This might be due to the hospital policy that stipulates which managers in the management hierarchy attend such meetings. However, participants indicated they were motivated because they were included in nursing management meetings and also they enjoyed good interpersonal relationships with other health care workers.

Participants indicated that authority to make decisions regarding material resources, patient care and unit budgets acted as positive aspects of their role. Having authority to make such decisions motivated the participants as a result they became committed to their work. Less than half of the participants indicated that they had the authority to mobilize resources. This means that most of the participants were not autonomous in their roles, thus they did not have power to influence the availability of resources, the behavior of their staff and the deli- 
very of nursing services. It is therefore important that unit nurse managers have the authority to source resources from alternative sources such as private companies, non-governmental organizations and other stakeholders. This enables the unit staff to maintain service delivery even when the hospital does not have resources, hence facilitating job satisfaction.

The semi-autonomous enactment of the unit nurse managers' role was also reflected in the findings; the unit nurse managers indicated they wanted support from the senior nurse managers in instilling disciplinary measures to the unit staff. Most often the participants failed to make important decisions such as taking disciplinary action because they lacked the authority to do so and were afraid to spoil relationships [19]. To effectively perform their role, nurse managers must be given authority to make decisions on matters involving delivery of patient care [19].

Results showed that participants mostly used management tools such as ward philosophy and objectives thus a very small number of the participants used policies to guide them in making decisions. It was indicated that participants did not use policies possibly because of lack of knowledge to interpret and understand them. It can also be that the policies were not available in their units. Working without adequate knowledge of the organization's policies can negatively affects the performance of the nurse managers. Nurse Managers must have knowledge and understanding of all management tools available in the organization to provide guidance and direction in decision making.

\subsection{Strategies to Improve Performance}

Participants proposed strategies that would improve the nurse managers' performance. They suggested availability of material and human resources, provision of support, training of personnel and enforcing use of management tools. These results concur with Loo and Thorpe [11] who in their study found that nurse managers made the following recommendations to management to improve their performance; provision of adequate resources, training in management and supportive work environment such as support from senior managers.

\section{Conclusion}

Participants in the study were aware of their managerial roles, responsibilities and skills that they need to have to perform their managerial role effectively. However, lack of or inadequate human and material resources were the major factors that hindered the performance of the participants as unit nurse managers. Good communication and interpersonal relationship among staff was the major factor that promoted their effective performance. Participants perceived their role to be stressful and challenging because of inadequate human, (especially nurses) and material resources. They did not perceive their educational preparation as one of the factors that could affect their performance in terms of skill acquisition. Furthermore the participants used the traditional approach of management to perform their role. This approach might not be effective for the complex health care environment in which they work.

\section{Recommendations}

To improve the level of performance of unit nurse managers in the two central hospitals, it is important that various stakeholders work together to create an enabling environment for the purpose of improving the delivery of quality nursing and health services in Malawi. Some recommendations were suggested for implementation or consideration by different stake holders. Nurse educators in health training institutions in consultation with other stakeholders should revise the curricula for training nurse managers in order to develop courses that will adequately prepare the nurses for the management role in the hospitals and other health care organizations. It is also important that Nurses and Midwives Council of Malawi as a regulatory body for nursing practice in Malawi should come up with performance standards for all nurse managers at different levels to guide their performance.

\section{Study Limitations}

The study was conducted in two central hospitals in Malawi which are tertiary referral facilities. Consequently the results may not be applicable to district and health center facilities, although the trend is similar to all health facilities at different levels in Malawi. 


\section{Acknowledgements}

This study was funded by the University of Malawi through Kamuzu College of Nursing as part of Masters Degree in Business Administration (MBA) for the senior author.

\section{Conflict of Interest}

None of the authors had any conflict of interest in the manuscripts being published in the Open Journal of Nursing.

\section{References}

[1] Buchan, J. and Poz, M. (2002) Skill Mix in the Health Care Workforce: Reviewing the Evidence. Bulletin of the World Health Organization, 80.

[2] Yoder-Wise, P.S. (2007) Leading and Managing in Nursing. Mosby/Elsevier, St. Louis.

[3] Craven, R.F. and Hirnle, C.J. (2009) Fundamentals of Nursing. 6th Edition, Wolters Kluwer/Lippincott Williams \& Wilkins, Philadelphia.

[4] Hewson, A. (2006) Management for Nurses and Health Professionals. Blackwell Science, Oxford.

[5] Robbins, S.P. and Coulter, M. (2002) Management. 7th Edition, Prentice Hall, New Jersey.

[6] National Statistical Office (NSO) and ICF Macro (2011) Malawi Demographic and Health Survey, 2010. NSO and ICF Marco, Zomba, Malawi, and Calverton, Maryland.

[7] Nurses and Midwives Council of Malawi (2009) Guidelines for Nurse Midwifery Practice in Malawi. NMCM, Lilongwe Malawi.

[8] Sim, J. and Wright, C. (2000) Research in Health Care. Nelson Thormes, The Netherlands.

[9] Mackoff, B.L. and Triolo, P.K. (2008) Why Do Nurse Managers Stay? Building a Model of Engagement. Journal of Nursing Administration, 38, 166-177. http://dx.doi.org/10.1097/01.NNA.0000312758.14536.e0

[10] Surakka, T. (2008) The Nurse Manager's Work in the Hospital Environment during the 1990s and 2000s: Responsibility, Accountability and Expertise in Nursing Leadership. Journal of Nursing Management, 16, 525-534. http://dx.doi.org/10.1111/j.1365-2834.2008.00901.x

[11] Loo, R. and Thorpe, K. (2003) Balancing Professional and Personal Satisfaction of Nurse Managers: Current and Future Perspectives in a Changing Health Care. Journal of Nursing Management, 11, 321-330. http://dx.doi.org/10.1046/j.1365-2834.2003.00397.x

[12] Jamal, F. and Baba, R. (2000) Job Analysis and Burn out among Canadian Managers and Nurses: An Empirical Examination. Canadian Journal of Public Health, 91, 454-458.

[13] Judkins, S., Massey, C. and Huff, B. (2006) Hardiness, Stress and Use of Illness among Nurse Managers. Is There a Connection? Journal of Nursing Economics, 24, 187-192.

[14] Wu, L.-M., Huang, J.-H., Tseng, I.-C., Lawler, J.J. and Vestal, K. (2007) Management Development: A Study of Nurse Managerial Activities and Skills. Journal of Healthcare Management, 52.

[15] Mathena, K.A. (2002) Nursing Manager Leadership Skills. Journal of Nursing Administration, 32, 136-142. http://dx.doi.org/10.1097/00005110-200203000-00006

[16] Gould, D., Kelly, D., Goldstone, L. and Maidwell, A. (2001) The Issues for Continuing Professional Development. Journal of Advanced Nursing, 34, 7-17. http://dx.doi.org/10.1046/j.1365-2648.2001.3411735.x

[17] Chirwa, M.L. (2000) What Specific Problems Do Nurse Managers in Malawi Report They Experience in Ensuring Quality Care. African Journal of Nursing and Midwifery November, 2.

[18] Aiken, L.H., Clarke, S. and Sloane, D.M. (2002) Hospital Staffing, Organization and Quality of Care: Cross-National Findings._Nursing Outlook, 50, 187-194. http://dx.doi.org/10.1067/mno.2002.126696

[19] McNeese-Smith, D.K. (2002) The Relationship between Managerial Motivation Leadership, Nurse Outcomes and Patient Satisfaction. Journal of Organizational Behavioral, 20, 243-259. 


\section{Abbreviations}

KCH: Kamuzu Central Hospital;

CNO: Chief Nursing Officer;

QECH: Queen Elizabeth Central Hospital;

ENM: Enrolled Nurse Midwife;

RN: Registered Nurse;

MDHS: Malawi Demographic Health Survey;

COMREC: College of Medicine Research and Ethics Committee;

WHO: World Health Organization. 
Scientific Research Publishing (SCIRP) is one of the largest Open Access journal publishers. It is currently publishing more than 200 open access, online, peer-reviewed journals covering a wide range of academic disciplines. SCIRP serves the worldwide academic communities and contributes to the progress and application of science with its publication.

Other selected journals from SCIRP are listed as below. Submit your manuscript to us via either submit@scirp.org or Online Submission Portal.
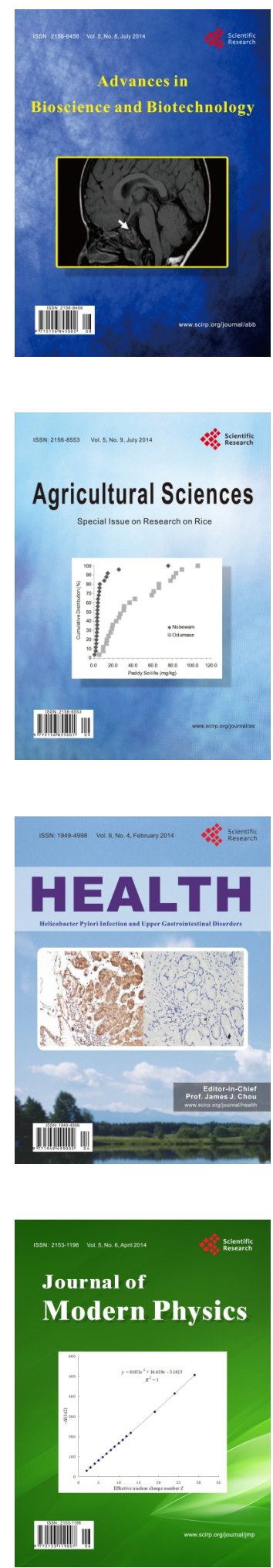
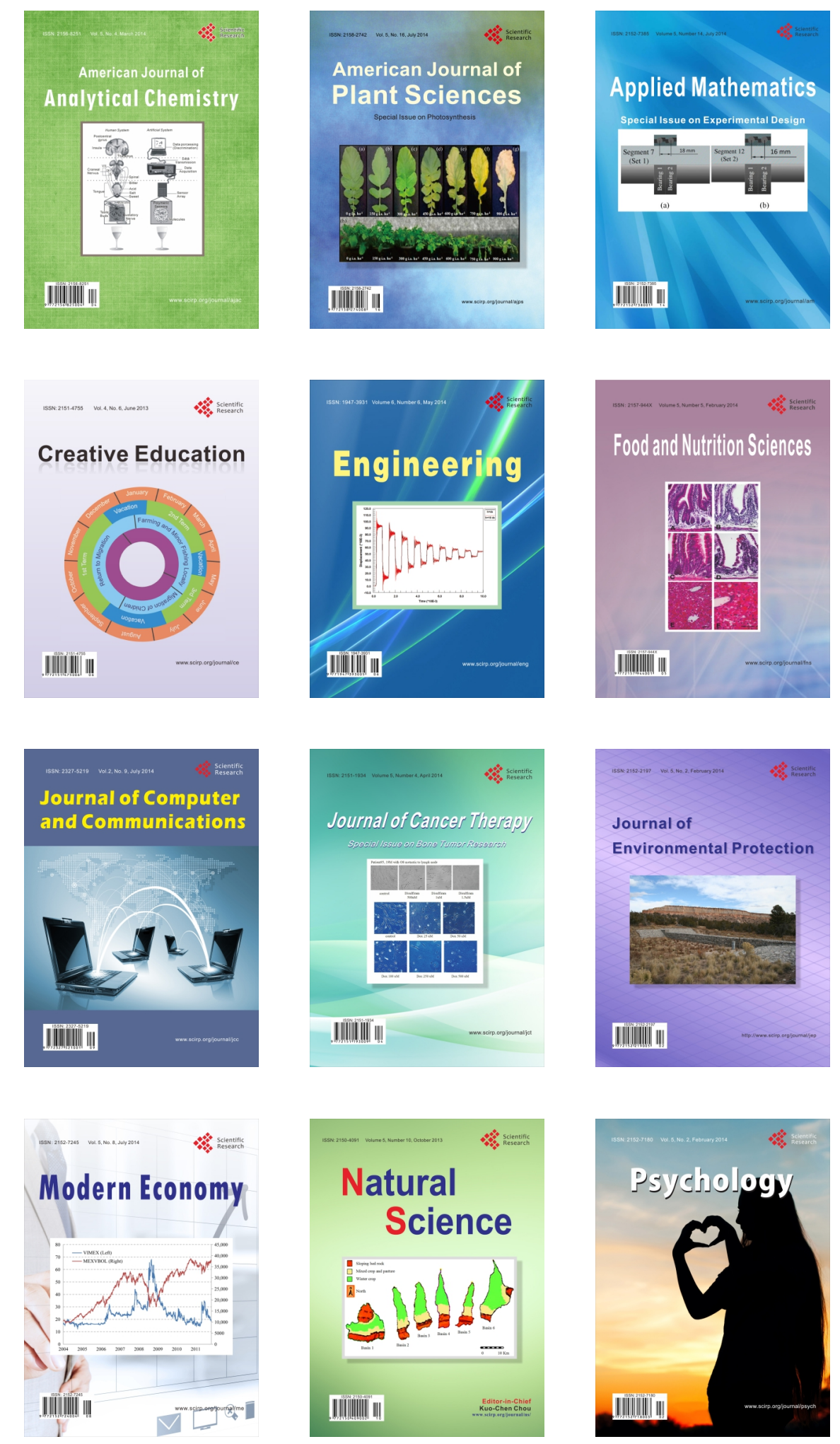